\title{
Effect of Nursing Educational Methods on the Quality of Bowel Cleanliness for Patients Undergoing Colonoscopy
}

\author{
Wafaa R. Ahmed, Mimi M. Makkawy, Zain Al-Abdeen A. Sayed \& Sahra Z. Azer. \\ Assistant Lecturer of Adult Nursing, Faculty of Nursing, Assiut University, Egypt. \\ professor of Adult Nursing, Faculty of Nursing, Assiut University, Egypt. \\ Assistant professor of Internal Medicine, Faculty of Medicine, Assiut University, Egypt. \\ Lecturer of Adult Nursing, Faculty of Nursing, Assiut University, Egypt.
}

\begin{abstract}
The aim of the study: to evaluate the effect of nursing educational methods on the quality of bowel cleanliness for patients undergoing colonoscopy. Research design: Quazi-experimental research design was be utilized. Subjects and methods: a purposive sample of 60 adult patients divided into two groups (control and study) 30 patients for each. A study conducted in Internal medicine, General surgery departments and Gastrointestinal Endoscopy Center at Assiut University Hospitals. Tools: Only one tool was being utilized; patient assessment sheet. Results: more than half of patients $(53.3 \%)$ in control group have bad level of bowel cleanliness with mean score of Boston bowel preparation scale (BBPS) was $(2.7 \pm 2.4)$, while more than half of patients in study group $(56.7 \%)$ have excellent level with mean score of (BBPS) was $(6.7 \pm 1.2)$. Conclusion: educating colonoscopy patient using nursing educational methods as video and booklet are considered a cornerstone in achieving accepted level of bowel cleanliness. Recommendation: Sufficient relevant written and visual information to facilitate educating patients about proper preparation of the bowel before colonoscopy and educating patients about signs and symptoms of the potential complications after colonoscopy for seeking rapid medical advice.
\end{abstract}

\section{Keywords: Nursing, Quality, Bowel, Cleanliness \& Colonoscopy.}

\section{Introduction}

Colonoscopy is a common procedure in medical practice for a variety of gastrointestinal indications. It is widely used in the United Stated, especially since 2001, when medicare expanded its coverage for screening for colorectal cancer to include colonoscopy (Sherid et al., 2013). An estimated 1114 million colonoscopies are performed in the United States annually (Peery et al., 2012).

A colonoscopy is a routine, safe, and effective procedure that healthcare providers use to visually examine the full lining of the colon and rectum. Colonoscopy is a procedure that uses a long, flexible, narrow tube with a light and tiny camera at one end, called a colonoscope (Green, 2015).

It is important that patients are educated and engaged in the colonoscopy preparations process, and it has been shown that effective education significantly improves the quality of bowel preparation. Patient counseling along with written instructions that are simple and easy to follow and in their native language should be provided to patients, and patient education may improve with the use of visual aids. Recently, educational booklets were shown to improve the quality of bowel preparation (Rosenfeld et al., 2010).

The success of colonoscopy depends on how well the colon is prepared. Adequate colon cleansing provides optimal visualization and decreases the time needed for the procedure. Cleansing of the colon can be accomplished in various ways. The physician may prescribe a laxative for two nights before the examination and a fleet's or saline enema until the return is clear on the morning of the test. The patient maintains a clear liquid diet starting at the day before the procedure (Smeltzer et al., 2008).

Examples of clear fluids are apple juice, chicken, and/or beef broth or bouillon, lemon-lime soda, lemonade, sports drink, and water. It is very important that the patient remains hydrated. Sports drinks contain electrolytes which are depleted during the purging of the bowel. Orange juice, prune juice, and milk containing fiber should not be consumed, nor should liquids dyed red, purple, orange, or sometimes brown; however, cola is allowed. In most cases, tea (no milk) or black coffee (no milk) are allowed (Wikipedia the free encyclopedia, 2015).

The day before the colonoscopy, the patient is either given a laxative preparation (such as Picosalax, Bisacodyl, soda, sodium, or sodium phosphate and/or magnesium citrate) and large quantities of fluid, or whole bowel irrigation is performed using a solution of polyethylene glycol and electrolytes. Often, the procedure involves both a pill-form laxative and a bowel irrigation preparation with the polyethylene glycol powder 
dissolved into any clear liquid, preferably a sports drink that contains electrolytes (Allen, 2010).

Consent is taken on the prescribed form, if available. The patient should wear the theater gown. Denture must be removed from the mouth, the blood pressure is recorded. Oxy- thermometer is put on in the finger. This will show the oxygen saturation of the peripheral blood in the tissue. A venous access is set up preferably in the dorsal vein of the right hand by inserting a fine venous cannula (Talley \& Kane, 2010).

The patient is asked to lie on the left lateral position bringing both knees towards the pelvis. The buttock is brought toward the edge of the couch, on the surgeon's side. In the middle of the procedure, if the difficulty is experienced in the advancing the colonoscope through the redundant sigmoid loop, the patient may need to be turned in the supine or right lateral position (Floch et al., 2010). During the procedure, the nurse monitors for changes in patient's oxygen saturation, vital signs, color and temperature of the skin, the level of consciousness, abdominal distention and pain intensity (Williams \& Paul, 2009).

Complications during and after the procedure can include cardiac dysrhythmias, respiratory depression, abdominal pain and discomfort, Gas explosion, circulatory overload or hypotension resulting from over hydration or under hydration during bowel preparation. Also, bleeding and colonic perforation may be occurred due to mechanical forces against the bowel wall (American Association of Gastrointestinal Endoscopy, 2011).

Written materials, such as brochures, pamphlets, patient pathways, and booklets are common in outpatient and inpatient areas of health care. They usually are inexpensive and offer opportunities for a wide range of education: disease process education, risk factors modifications information, procedure education, medication education, and use of medical equipment in the home setting. Written materials address multiple learning styles and offer learnercentered teaching with concrete, basic information that can be placed at the learner's fingertips for immediate reviews, as well as future review any time the learner desires. The practitioner must make sure that written materials are appropriate for the patient population as a whole and for a particular individual patient or family (Urden et al., 2014).

Videos are an option for distributing patient education information. Videos about various medical topics are produced and electronically distributed by pharmaceutical companies, hospitals, and office practices. This method is especially helpful for demonstrating skills because the video can be replayed and stopped. This method is effective because it take advantages of more than one route for imparting information. It is also independent of reading level. It is cheapest to lend the DVD to the patient for home viewing, with subsequent return to the practice when finished (Muma \& Lyons, 2012).

\section{Significance of the Study}

The researcher observed that the patients undergoing colonoscopy needed special nursing preparations to improve the quality of bowel cleanliness and minimize the incidence of risks and complications. This research considers the first one in this area caring for patients undergoing colonoscopy. In 2014, (540) patients had performed colonoscopy procedures in the Gastrointestinal Endoscopy Center (Assiut University Hospital Statistical Records, 2014), many cases of them were canceled and repeated the procedure due to difficult visualization of the colon and inadequate bowel preparations and this can lead to increase the economic impact by prolonging the procedure time and the hospital stay.

\section{The aim of the study}

To evaluate the effect of educational methods on the quality of bowel cleanliness for patients undergoing colonoscopy.

\section{Hypothesis}

To fulfill the aim of the study the following research hypothesis was formulated:-

1. The mean score level of Boston bowel preparation scale in the study group will be higher than that score in the control group.

2. The incidence of colonoscopy problems and complications in patients at study group will be less than that in patients at control group.

Operational definitions

Quality: the standard of something as measured against other things of a similar kind; the degree of excellence of something

Colonoscopy: an Invasive procedure that uses a long, flexible, narrow tube with a light and tiny camera at one end, called a colonoscope.

\section{Patients \& Methods}

\section{Research design}

Quazi-experimental research design was utilized in this study.

\section{Study variables}

The independent variable in this study was the nursing educational methods (video and booklet). While the dependent variable was the quality of bowel preparation. 


\section{Setting}

The study was conducted in Gastrointestinal Endoscopy Center, internal medicine, and general surgery departments at Assiut University Hospital.

\section{Patients}

A purposive sample of 60 adult patients undergoing colonoscopy procedure divided into two groups (control and study) 30 patients for each. The study group was selected according to the following criteria: Adult conscious patients undergoing colonoscopy, both sexes (male and female), age range between (18 - 65 years), and ability to complete the participation in the research regardless educational level.

- Control group: 30 patients received routine nursing instructions at their units and there is no any participation from the researcher for educating them.

- Study group: 30 patients received nursing educational booklet and video; each patient received the instructions in one session one to two days before colonoscopy according to a policy of the center.

Tools:

The tool of the study was utilized for data collection was:

Tool I: Patient assessment sheet:

It was developed by the researcher based on the literature review. It was consisted of three main parts:

Part I: Pre-colonoscopy assessment. It included:

Socio-demographic data of study sample (60 patients) such as: Patient's name, age, gender, marital status, occupation, the level of education, and residence, a general assessment of medical diagnosis, family history, and the reason for colonoscopy.

\section{Part II: Boston Bowel Preparation Scale (BBPS)}

The BBPS was developed by the section of gastroenterology at Boston Medical Center (BMC), published in October 2010 in the journal of Gastrointestinal Endoscopy to provide a muchneeded standard for assessing the quality of bowel preparation for colonoscopy. (Fig. 1).

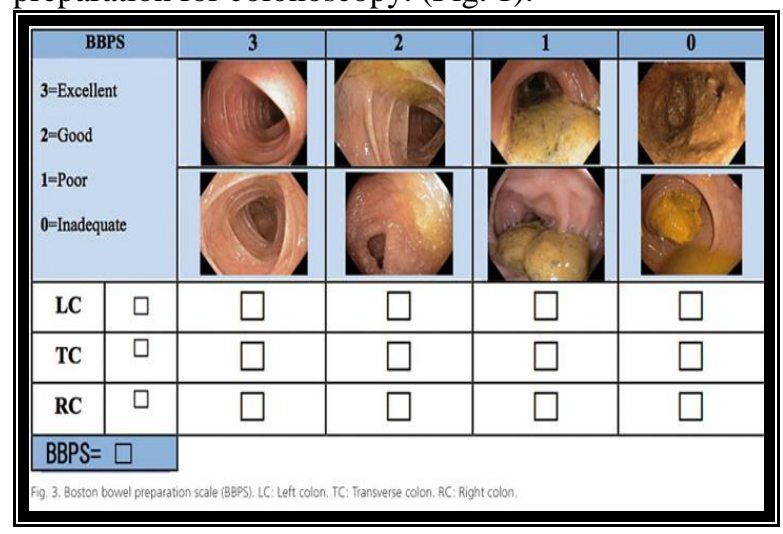

(Fig.1): Boston Bowel Preparation Scale. Adopted from (Zúñiga, Moreno-de-Vega, and Boix (2012).

- LC: Left colon

- TC: Transverse colon

- RC: Right colon

Scoring system: The maximum Boston bowel preparation scale (BBPS) score for a perfectly clean colon without any residual liquid is 9 and the minimum BBPS score for an unprepared colon is 0 . Excellent (more than 7 degrees), Fair (4 - 6 degrees) and Bad (less than 3 degrees).

Part III: Assessment of post colonoscopy problems and complications

This part was utilized to assess colonoscopy problems such as difficult visualization of the colon, prolonged procedure time ( $>1 \mathrm{hr}$.), and canceled and repeated colonoscopy, and post-colonoscopy complications such as abdominal pain, abdominal distension, hypoxia, chest pain, tachycardia, cardiac dysrhythmias, respiratory depression. Hypertension, hypotension, bleeding, perforation, gas explosion, vomiting, fever or post-polypectomy electrocoagulation syndrome.

Colonoscopy preparation educational methods: It consisted of two main parts:

Part I: Colonoscopy preparation video

A ten minutes colonoscopy education video presented by Dr. Ahmed El-fadly, consultant of gastroenterology at Mubarak hospital at Al- Kuwait country published at YouTube in November 2012.This video contains oral presentation about anatomy of the colon, definition, and importance of colonoscopy, brief explanation about preparation before colonoscopy, what will happen during colonoscopy?, colonoscopy problems and complications and what will happen post colonoscopy?.

Part II: Nursing educational booklet

It developed by the researcher based on the review of the relevant literature to provide colonoscopy patients with needed instructions to obtain accurate bowel preparation before colonoscopy and to minimize the incidence of colonoscopy problems and complications.

The nursing educational booklet included anatomy and function of the colon, definition of colonoscopy, why it is important to get cleaned colon precolonoscopy?, preparing for colonoscopy, permitted and avoided foods and drinks, what will happen during colonoscopy?, warning signs post colonoscopy and what will happen post colonoscopy?.

Methods

Administrative approval: An official permission was obtained from the head of the gastrointestinal endoscopy Center, internal medicine and general 
surgery departments at Assiut university hospital to conduct the study.

Patient assessment sheet was developed by the researcher after an extensive review of the relevant literature. The tool was tested for content validity by 5 experts of academic medical and nursing staff at Assiut University. Modifications were done accordingly, and then the tool was designed in its final format and tested for reliability by using internal consistency for the tools measured using Cronbach test, the tools proved to be reliable (0.73).

Ethical considerations: An oral permission for voluntary participation was obtained from patients and the nature and purposes of the study were explained. The researcher initially introduced himself to all patients and they were assured that the collected data would be absolutely confidential. Patients were informed that participation is voluntary and that they could withdraw at any time of the study. Confidentiality of the patient's data was ascertained. Confidentiality and anonymity were assured. Patient's names were coded for data entry so that their names could not be identified.

Pilot study: A pilot study was conducted on $10 \%$ of the sample (6 patients) in a selected setting to evaluate the applicability \& clarity of the tools. According to this pilot study, the required modifications were made. Those patients who were involved in the pilot study were not included in the study.

\section{Data collection}

The data collection was done through the following phases:

\section{Assessment phase}

- The researcher interviewed the patients who were requested for a colonoscopy at general surgery and internal medicine departments and get their oral consent to participate in the study.

- Categorization of patients to two groups (30 patients for each) was done. Patient assessment sheet (tool I, part I) was applied which is concerned with patient's sociodemographic data (patient's name, age, gender, marital status, occupation, the level of education, and residence) and general assessment about medical diagnosis, family history, and the reason for colonoscopy.

- Patient assessment sheet ( a tool I, part I) was applied on every patient individually at the two groups.

Implementation phase

- The first group of patients (30 patients) received routine nursing instructions, (there is no any participation from the researcher for educating patient or colon preparation for colonoscopy and they considered as a control group).

- The second group of patients received nursing educational booklet and video; each patient received the instructions in one session one to two days before colonoscopy according to a policy of the center.

- The session takes 15-30 minutes. After each session, there was 5-10 minutes for discussion and gave feedback.

- Reinforcement of teaching was performed according to patient's needs to ensure their understanding.

- Each patient in the group obtained a copy of the teaching booklet; the researcher used pictures for illustration, diagram, and laptop to visualize patients the educational video. Patients who have smart phones or laptop can obtain a copy from the video.

Evaluation phase

- At the day of colonoscopy the researcher met every patient of the two groups at the gastrointestinal endoscopy center and the researcher assess the quality of bowel preparation using Boston bowel preparation scale (Tool I part II) intracolonoscopy.

- Each patient obtained a score from 9 to reflect the effect of the educational method on the quality of bowel preparation.

- The researcher assessed the problems and complications (Tool I part III) that happened during colonoscopy procedure and following up the patient for three days after colonoscopy to assess the complications that may happen at their units (general surgery or internal medicine departments).

Statistical design Data collected and analyzed by computer program SPSS" ver. 20" Chicago, USA. Data expressed as mean, Standard Deviation, number, and Percentage. Using T.test to determine significantly for the numeric variable. Using Chisquare to determine significant for the non-parametric variable.

\section{Limitation of the study}

- The preparation period of the patient before colonoscopy not enough because Gastro Endoscopy unit specified the procedure time from 24-48 hrs after receiving colonoscopy request from medical or surgical units at Assiut university hospital.

- The level of literacy in patient population limits their ability to access or benefit from some parts of the educational booklet because of lack in their reading abilities.

- The majority of patients who received colonoscopy preparation video haven't a laptop or smart phones so; the patients received the video only once using the researcher's laptop. 


\section{Results}

Table 1: Frequency distribution of socio-demographic characteristics of control and study groups of patients undergoing colonoscopy (pre - colonoscopy).

\begin{tabular}{|c|c|c|c|c|c|}
\hline \multirow[t]{2}{*}{ Variables } & \multicolumn{2}{|c|}{$\begin{array}{c}\text { Control group } \\
(n=30)\end{array}$} & \multicolumn{2}{|c|}{$\begin{array}{l}\text { Study group } \\
\quad(\mathbf{n}=\mathbf{3 0})\end{array}$} & \multirow[t]{2}{*}{ P. value } \\
\hline & No. & $\%$ & No. & $\%$ & \\
\hline \multicolumn{5}{|l|}{ Age } & \multirow{4}{*}{$0.735 \mathrm{~ns}$} \\
\hline $18<30$ years & 9 & 30.0 & 5 & 16.7 & \\
\hline $30-50$ years & 14 & 46.7 & 17 & 56.7 & \\
\hline$>50$ years & 7 & 23.3 & 8 & 26.7 & \\
\hline Mean \pm SD & \multicolumn{2}{|c|}{$40.8+13.3$} & \multicolumn{2}{|c|}{$42.0+12.0$} & $0.601 \mathrm{~ns}$ \\
\hline \multicolumn{5}{|l|}{ Gender } & \multirow{3}{*}{$0.784 n s$} \\
\hline Male & 16 & 53.3 & 18 & 60.0 & \\
\hline Female & 14 & 46.7 & 12 & 40.0 & \\
\hline \multicolumn{5}{|l|}{ Marital status } & \multirow{4}{*}{$0.507 \mathrm{~ns}$} \\
\hline Single & 4 & 13.3 & 3 & 10.0 & \\
\hline Married & 21 & 70.0 & 23 & 76.7 & \\
\hline Widow /widower & 5 & 16.7 & 4 & 13.3 & \\
\hline \multicolumn{5}{|l|}{ Level of education } & \multirow{6}{*}{$0.740 \mathrm{~ns}$} \\
\hline High education & 2 & 6.7 & 6 & 20.0 & \\
\hline Secondary edu. & 9 & 30.0 & 8 & 26.7 & \\
\hline Basic education & 7 & 23.3 & 4 & 13.3 & \\
\hline Read and write & 1 & 3.3 & 1 & 3.3 & \\
\hline Illiterate & 11 & 36.7 & 11 & 36.7 & \\
\hline \multicolumn{5}{|l|}{ Occupation } & \multirow{6}{*}{$0.506 \mathrm{~ns}$} \\
\hline Employee & 7 & 23.3 & 8 & 26.7 & \\
\hline Farmer & 3 & 10.0 & 4 & 13.3 & \\
\hline Housewife & 12 & 40.0 & 11 & 36.7 & \\
\hline Student & - & - & 2 & 6.7 & \\
\hline Skilled worker & 8 & 26.7 & 5 & 16.7 & \\
\hline \multicolumn{5}{|l|}{ Residence } & \multirow{3}{*}{$0.247 \mathrm{~ns}$} \\
\hline Urban & 6 & 20.0 & 10 & 33.3 & \\
\hline Rural & 24 & 80.0 & 20 & 66.7 & \\
\hline
\end{tabular}

Ns: Not significant

Table (2): Frequency distribution of medical diagnosis and family history of control and study groups of patients undergoing colonoscopy (pre - colonoscopy).

\begin{tabular}{|c|c|c|c|c|c|}
\hline \multirow{2}{*}{ Variables } & \multicolumn{2}{|c|}{ Control group $(n=30)$} & \multicolumn{2}{|c|}{ Study group $(n=30)$} & \multirow[t]{2}{*}{ P. value } \\
\hline & No. & $\%$ & No. & $\%$ & \\
\hline \multicolumn{5}{|l|}{ Medical diagnosis } & \multirow{7}{*}{$0.866 \mathrm{~ns}$} \\
\hline Ulcerative colitis & 7 & 23.3 & 7 & 23.3 & \\
\hline Crohns disease & 7 & 23.3 & 3 & 10.0 & \\
\hline Iron deficiency anemia & 8 & 26.7 & 5 & 16.7 & \\
\hline Colorectal cancer & 4 & 13.3 & 7 & 23.3 & \\
\hline Internal piles & 3 & 10.0 & 4 & 13.3 & \\
\hline Others: & 1 & 3.3 & 4 & 13.3 & \\
\hline \multicolumn{5}{|c|}{ Family history of the diagnosis } & \multirow[b]{3}{*}{$0.513 \mathrm{~ns}$} \\
\hline Yes & 2 & 6.7 & 1 & 3.3 & \\
\hline No & 28 & 93.3 & 29 & 96.7 & \\
\hline
\end{tabular}

Ns: Not significant 
Table (3): Frequency distribution of reason of colonoscopy of control and study groups of patients undergoing colonoscopy (pre - colonoscopy).

\begin{tabular}{|c|c|c|c|c|c|}
\hline \multirow{2}{*}{ Variables } & \multicolumn{2}{|c|}{ Control group $(n=30)$} & \multicolumn{2}{|c|}{ Study $\operatorname{group}(\mathrm{n}=30)$} & \multirow{2}{*}{ P. value } \\
\hline & No. & $\%$ & No. & $\%$ & \\
\hline \multicolumn{5}{|l|}{ Diagnostic } & \multirow{7}{*}{$0.342^{\mathrm{ns}}$} \\
\hline Rectal bleeding & 10 & 33.3 & 13 & 43.3 & \\
\hline Change in bowel habits (chronic diarrhea). & 3 & 10.0 & 2 & 6.7 & \\
\hline Rectal bleeding \& change in bowel habits & 2 & 6.7 & 2 & 6.7 & \\
\hline Change in bowel habits \& un explained weight loss & 3 & 10.0 & 2 & 6.7 & \\
\hline Change in bowel habits \& abdominal pains & 6 & 20.0 & 4 & 13.3 & \\
\hline Un explained weight loss \& abdominal pain & - & - & 2 & 6.7 & \\
\hline \multicolumn{5}{|l|}{ Therapeutic } & \multirow{4}{*}{$0.362 \mathrm{~ns}$} \\
\hline Polypectomy & 1 & 3.3 & 3 & 10.0 & \\
\hline Bleeding treatment & - & - & - & - & \\
\hline Tissue biopsy & 11 & 36.7 & 15 & 50.0 & \\
\hline
\end{tabular}

Table (4): Frequency distribution of mean score and levels of Boston bowel preparation scale (BBPS) of control and study groups of patients undergoing colonoscopy (intra -colonoscopy).

\begin{tabular}{|c|c|c|c|c|c|}
\hline \multirow{2}{*}{ Variables } & \multicolumn{2}{|c|}{ Control group $(n=30)$} & \multicolumn{2}{|c|}{ Study group $(\mathbf{n}=\mathbf{3 0})$} & \multirow[t]{2}{*}{ P. value } \\
\hline & No. & $\%$ & No. & $\%$ & \\
\hline \multicolumn{5}{|l|}{ BBPS } & \multirow{4}{*}{$<0.001 * *$} \\
\hline Bad & 16 & 53.3 & - & - & \\
\hline Fair & 12 & 40.0 & 13 & 43.3 & \\
\hline Excellent & 2 & 6.7 & 17 & 56.7 & \\
\hline Mean+SD & \multicolumn{2}{|c|}{$\frac{1}{2.7 \pm 2.4}$} & \multicolumn{2}{|c|}{$6.7+1.2$} & $<0.001$ *** \\
\hline
\end{tabular}

N.B. total score of the scale is 9: Excellent (more than 7 degrees). Fair (4 - 6 degrees). Bad (less than 3 degrees).

Table (5): Frequency distribution of problems and complications of control and study groups of patients undergoing colonoscopy (intra and post- colonoscopy).

\begin{tabular}{|c|c|c|c|c|c|}
\hline \multirow{2}{*}{ Variables } & \multicolumn{2}{|c|}{$\begin{array}{c}\text { Control group } \\
(\mathbf{n}=\mathbf{3 0})\end{array}$} & \multicolumn{2}{|c|}{$\begin{array}{c}\text { Study group } \\
(\mathbf{n}=\mathbf{3 0})\end{array}$} & \multirow[t]{2}{*}{ P. value } \\
\hline & No. & $\%$ & No. & $\%$ & \\
\hline \multicolumn{6}{|l|}{ Problems } \\
\hline Difficult visualization of the colon. & 23 & 76.7 & - & - & $<0.001 * *$ \\
\hline Canceled and repeated colonoscopy. & 12 & 40.0 & - & - & $<0.001 * *$ \\
\hline \multicolumn{6}{|l|}{ Complications } \\
\hline Abdominal pain or discomfort & 18 & 60.0 & 30 & 100.0 & $<0.001 * *$ \\
\hline Abdominal distention (bloating) & 14 & 46.7 & 25 & 83.3 & 0.008 ** \\
\hline Tachycardia. & 4 & 13.3 & - & - & $0.269 \mathrm{~ns}$ \\
\hline Cardiac dysrhythmias. & 1 & 3.3 & - & - & $0.388 \mathrm{~ns}$ \\
\hline Hypertension & 2 & 6.7 & 4 & 13.3 & $0.655 \mathrm{~ns}$ \\
\hline Hypotension & 6 & 20.0 & - & - & $0.057 \mathrm{~ns}$ \\
\hline Vomiting & - & - & 1 & 3.3 & $0.795 \mathrm{~ns}$ \\
\hline
\end{tabular}


Table (6): Relation between sociodemographic characteristics of patients and quality of bowel cleanliness according to Boston bowel preparation scale.

\begin{tabular}{|c|c|c|c|c|c|c|c|}
\hline & \multicolumn{6}{|c|}{ BBPS } & \multirow{3}{*}{ P. value } \\
\hline & \multicolumn{2}{|c|}{ Bad } & \multicolumn{2}{|c|}{ Fair } & \multicolumn{2}{|c|}{ Excellent } & \\
\hline & No. & $\%$ & No. & $\%$ & No. & $\%$ & \\
\hline \multicolumn{7}{|l|}{ Age } & \multirow{4}{*}{$0.841 \mathrm{~ns}$} \\
\hline $18-30$ years & 5 & 21.7 & 17 & 29.8 & 8 & 20.0 & \\
\hline $30-50$ years & 11 & 47.8 & 24 & 42.1 & 20 & 50.0 & \\
\hline$>50$ years & 7 & 30.4 & 16 & 28.1 & 12 & 30.0 & \\
\hline \multicolumn{7}{|l|}{ Sex } & \multirow{3}{*}{$0.445 \mathrm{~ns}$} \\
\hline Male & 14 & 60.9 & 27 & 47.4 & 23 & 57.5 & \\
\hline Female & 9 & 39.1 & 30 & 52.6 & 17 & 42.5 & \\
\hline \multicolumn{7}{|l|}{ Marital status } & \multirow{4}{*}{$0.707 \mathrm{~ns}$} \\
\hline Single & 2 & 8.7 & 6 & 10.5 & 7 & 17.5 & \\
\hline Married & 16 & 69.6 & 40 & 70.2 & 28 & 70.0 & \\
\hline Widow & 5 & 21.7 & 11 & 19.3 & 5 & 12.5 & \\
\hline \multicolumn{7}{|l|}{ Level of education } & \multirow{6}{*}{$0.181 \mathrm{~ns}$} \\
\hline High education & 1 & 4.3 & 4 & 7.0 & 10 & 25.0 & \\
\hline Secondary education & 10 & 43.5 & 17 & 29.8 & 11 & 27.5 & \\
\hline Basic education & 5 & 21.7 & 11 & 19.3 & 6 & 15.0 & \\
\hline Read and Write & 1 & 4.3 & 1 & 1.8 & 1 & 2.5 & \\
\hline Illiterate & 6 & 26.1 & 24 & 42.1 & 12 & 30.0 & \\
\hline \multicolumn{7}{|l|}{ Occupation } & \multirow{6}{*}{$0.273 \mathrm{~ns}$} \\
\hline Employee & 8 & 34.8 & 10 & 17.5 & 13 & 32.5 & \\
\hline Farmer & 4 & 17.4 & 9 & 15.8 & 7 & 17.5 & \\
\hline House wife & 6 & 26.1 & 24 & 42.1 & 13 & 32.5 & \\
\hline Student & - & - & 1 & 1.8 & 3 & 7.5 & \\
\hline Skilled worker & 5 & 21.7 & 13 & 22.8 & 4 & 10.0 & \\
\hline \multicolumn{7}{|l|}{ Residence } & \multirow{3}{*}{$0.003 * *$} \\
\hline Urban & 5 & 21.7 & 7 & 12.3 & 17 & 42.5 & \\
\hline Rural & 18 & 78.3 & 50 & 87.7 & 23 & 57.5 & \\
\hline
\end{tabular}

Table (7): Relation between problems and complications of patients and total score categories of Boston bowel preparation scale.

\begin{tabular}{|c|c|c|c|c|c|c|c|}
\hline \multirow{3}{*}{ Variables } & \multicolumn{6}{|c|}{ BBPS } & \multirow[t]{3}{*}{ P. value } \\
\hline & \multicolumn{2}{|c|}{ Bad } & \multicolumn{2}{|c|}{ Fair } & \multicolumn{2}{|c|}{ Excellent } & \\
\hline & No. & $\%$ & No. & $\%$ & No. & $\%$ & \\
\hline Difficult visualization of the colon. & 23 & 100 & 13 & 22.8 & - & - & $<0.001 * *$ \\
\hline Canceled \& repeated colonoscopy. & 19 & 82.6 & - & - & - & - & $<0.001 * *$ \\
\hline Abdominal pain or discomfort & 4 & 17.4 & 57 & 100 & 39 & 97.5 & $<0.001 * *$ \\
\hline Abdominal distention.(bloating) & 1 & 4.3 & 47 & 82.5 & 34 & 85 & $<0.001 * *$ \\
\hline Tachycardia. & 2 & 8.7 & 3 & 5.3 & 5 & 12.5 & $0.443^{\mathrm{ns}}$ \\
\hline Cardiac dysrhythmias. & - & - & 1 & 1.8 & - & - & $0.573^{\text {ns }}$ \\
\hline Hypertension & - & - & 10 & 17.5 & 4 & 10 & $0.081^{\text {ns }}$ \\
\hline Hypotension & 2 & 8.7 & 4 & 7.0 & 5 & 12.5 & $0.652^{\mathrm{ns}}$ \\
\hline Vomiting & - & - & 1 & 1.8 & 2 & 5.0 & $0.418^{\text {ns }}$ \\
\hline
\end{tabular}


Table (1): Illustrated that, more than half of patients in control and study groups were males $(53.3 \%$ \& $60 \%)$, married, their mean ages were $(40.8 \pm 13.3$ $\& 42.0 \pm 12.0)$ for control and study group respectively. Regarding the level of education; more than one-third of patients $(36.7 \%)$ at both control and study groups were illiterates, housewives with $(40 \%$ $\& 36.7 \%$ ) for control and study groups respectively. The majority of patients at both groups were lived in rural areas. Finally, the table shows that there is no statistically significant difference between the two groups regarding sociodemographic characteristics of patients undergoing colonoscopy.

Table (2): Showed that, in one hand more than onequarter of patients in the control group were diagnosed as ulcerative colitis, Crohn's disease (23.3\%), and iron deficiency anemia (26.7\%). On the other hand, more than one-quarter of patients in the study group were diagnosed with ulcerative colitis and colorectal cancer with $(23.3 \%)$ for each diagnosis. Also, the majority of the patient in the two study groups haven't a family history of the diagnosis. The table shows that there is no statistically significant difference between the two groups regarding medical diagnosis and family history of the diagnosis of patients undergoing colonoscopy.

Table (3): Mentioned that, more than one-third of patients $(33.3 \% \& 43.3 \%)$ at control and study groups were suffering from rectal bleeding. Also, one-third of the patients in control group (36.7\%) and half of the patients in the study group $(50 \%)$ were performed therapeutic colonoscopy and tissue biopsies were taken. The table showed that there is no statistically significant difference between the two groups regarding reasons of colonoscopy.

Table (4): Showed that more than half of patients in control group $(53.3 \%)$ have bad level of bowel cleanliness and mean score of BBPS was $(2.7 \pm 2.4)$, while more than half of patients study groups $(56.7 \%)$ have excellent level of bowel cleanliness and mean score of BBPS was $(6.7 \pm 1.2)$. As regard to Boston bowel preparation scale; there is high $(\mathrm{P}<0.001)$ statistically significantly different in the cleaning level of the colon and mean score of BBPS.

Table (5): Illustrated that a statistically significant difference between control and study group of patients undergoing colonoscopy related to difficult visualization of the colon, canceled and repeated colonoscopy, abdominal pain or discomfort and abdominal distension (bloating). While the other items as (tachycardia, cardiac dysrhythmias, and hypotension) show a decrease in the incidence but not reach to a statistically significant difference.

Table (6): showed that there was no significant relation (negative relation) between the ages, sexes, marital status, the level of education and occupation of patients and total score categories of Boston bowel preparation scale. While there was highly significant relation (positive relation) between the residences of study groups and total score categories of Boston bowel preparation scale.

Table (7): illustrated that there was a highly statistically significant difference related to difficult visualization of the colon, canceled and repeated colonoscopy, abdominal pain or discomfort and abdominal distension (bloating). While the other items as (tachycardia, cardiac dysrhythmias, hypertension, and hypotension) show no statistically significant difference.

\section{Discussion}

Based on the results of the present study, more than half of patients in control and study groups were males, married, their mean ages were $(40.8 \pm 13.3$ $\& 42.0 \pm 12.0$ ) for control and study group respectively. (Voiosu, et al., 2013); in the same line with the study findings and reported that; more than half of patients of the study sample were male. Also, (Shieh et al., 2013); revealed that more than half of patients in the education group and in the control group were men. The mean age of patients in the education group was $46.1 \pm 10.9$ years, and in the control group was $52.8 \pm 14.3$ years.

Regarding the level of education; more than one-third of patients in both control and study groups were illiterates, housewives. This result was in the same line with (Van Jaarsveld, et al., 2006); who revealed that; married adults are more likely to participate in colorectal cancer screening colonoscopy than the non-married, and inviting both members of a couple together further increases screening uptake. The positive effect of marriage was as strong for women as men.

The majority of patients at both groups were lived in rural areas. The current study findings disagreed with (Henry, 2015) who revealed that; little is known about the effects of geographic factors, such as rural versus urban residence and travel time to colonoscopy providers, on risk-appropriate use of colorectal cancer (CRC) screening in the general population. More than half of the sample adhered to risk-appropriate $\mathrm{CRC}$ screening guidelines, with significant differences between urban and rural residents across all familial risk groups. Rural residents were less likely than urban dwellers to be up-to-date with screening guidelines.

As regard, the medical diagnosis; more than onequarter of patients in the control group were diagnosed as ulcerative colitis, Crohn's disease, and iron deficiency anemia. On the other hand, more than 
one-quarter of patients in the study group were diagnosed with ulcerative colitis and colorectal cancer. (Habr-Gama, et al., 2015); was agree with the finding of our study and mentioned that; colonoscopy can be used to diagnose and evaluate the extent and severity of ulcerative colitis, which can be useful in guiding medical therapy and in the consideration of surveillance examinations. Intubation of the terminal ileum and biopsy can be useful in distinguishing ulcerative colitis from Crohn's disease; colonoscopy and sigmoidoscopy with biopsy are often used to assess histological improvement as a measure of the effectiveness of a medical treatment.

Also, (Nolan, 2011); reported that; since anemia can result from a variety of causes (from inflammation in the colon to colon cancer), there are many optional screening tests that can be administered in an attempt to discover the underlying condition. A colonoscopy procedure will determine whether a patient has pouches (diverticulum) or polyps that are causing bleeding or inflammation in the large intestine. Gastrointestinal bleeding or ulcer is another example of a condition that may cause significant blood loss in a patient diagnosed with anemia.

According to (Zauber et al., 2012); who reported that; screening for colorectal cancer (CRC) in asymptomatic patients can reduce the incidence and mortality. In the United States, colonoscopy has become the most commonly used screening test. Adenomatous polyps are the most common neoplasm found during CRC screening. There is evidence that detection and removal of these cancer precursor lesions may prevent many cancers and reduce mortality.

The current study showed that more than one-third of patients in control and study group were suffering from rectal bleeding. Also, one-third of the patients control group and half of the patients in study group perform therapeutic colonoscopy and tissue biopsies were taken.

This result from the researcher opinion is due to increase the number of patients diagnosed as ulcerative colitis, Crohn's disease and colorectal cancer and rectal bleeding is the most common symptom of these diseases. The study finding was in the same line with (Nordqvist, 2013). who reported that; symptoms of ulcerative colitis include bloody diarrhea, which may be associated with crampy abdominal pain and sudden urgency to have a bowel movement. Loss of appetite, weight loss, and fatigue are also common symptoms. In cases of severe bleeding, anemia may occur.

Also, (American Cancer Society, 2015); reported that; colorectal cancer may cause one or more of these symptoms as a change in bowel habits (such as diarrhea, constipation that lasts for more than a few days), rectal bleeding, blood in the stool, which may cause dark stool, cramping or abdominal pain, weakness, fatigue and unexplained weight loss. In the case of lower gastrointestinal (GI) bleeding, colonoscopy can be useful to not only localize the site of bleeding but also as a potential for therapeutic intervention.

(Warner, 2014), was also in the same line and reported that; According to a study published in the scientific journal of Gastroenterology, the risk of colorectal cancer among people with ulcerative colitis ranges from about 2 percent after 10 years of the disease $8 \%$ after 20 years to 18 percent after 30 years of the disease, and (Mattar, et al., 2011); which revealed that" The crude annual incidence rate of colorectal cancer in ulcerative colitis ranges from approximately $0.06 \%$ to $0.16 \%$, with a relative risk of 1.0-2.75. The exact mechanism for this change is unknown; it may partly be explained by the most widespread use of maintenance therapy and surveillance colonoscopy.

This results of the current study showed that more than half of patients in the control group have a bad level of bowel cleanliness while more than half of patients at study group have an excellent level of bowel cleanliness. As regard to Boston bowel preparation scale; there is high statistically significantly different in the cleaning level of the colon of the two groups of patients undergoing colonoscopy.

These results from the researcher's opinion were due to receive the patients educational instructions about preparing the colon before colonoscopy by using audiovisual aids as an educational booklet and video. (Bastable et al., 2011); was agree with the researcher's opinion and reported that; the instructional materials assist the nurse to deliver messages creatively and clearly during patient education. A multimedia approach to teaching helps learners to retain effectively what they learn, helps clarify abstract or complex concepts, adds variety to teaching- learning experience reinforces learning and potentially brings realism to the experience. It is well documented that the use of audiovisual aids facilitates learning. Therefore, nurses must look for ways to supplement their teaching with methods that help the learner to more easily acquire knowledge, attitudes, and skills.

The results of the current study revealed that more than two-thirds of patients at control group have a difficult visualization of the colon during colonoscopy and so, nearly half of these patients canceled the procedure and repeated colonoscopy was done for them. (Chan, et al., 2011); agree with these findings which revealed that; unfortunately, up 
to $20-25 \%$ of all colonoscopies are reported to have an inadequate bowel preparation. The reasons for this range from patient-related variables such as compliance with preparation instructions and a variety of medical conditions that make bowel cleansing more difficult to unit-specific factors (eg, extended wait times after scheduling of colonoscopy). Adverse consequences of ineffective bowel preparation include lower adenoma detection rates, longer procedural time, lower cecal intubation rates, increased electrocautery risk, and shorter intervals between examinations.

according to (Zuccala, 2015); who mentioned that; an improperly prepared bowel increases cost related to repeating the procedure; and leads to dissatisfied patients. High-quality bowel preparation is essential for a successful colonoscopy and involves dedication and persistence on the part of the patients. adequate bowel preparation is associated with shorter procedure time and complete visualization of the entire colon (enabling a successful procedure).

Also, (Hassan, et al., 2013); reported that; an adequate level of cleansing is critical for the efficacy of colonoscopy. Two key quality indicators of colonoscopy, cecal intubation rate, and polyp detection rate, are associated with the quality of bowel cleansing. An inadequate level of bowel cleansing also results in further costs as the examination has to be re-scheduled or alternative investigations have to be organized. Furthermore, the discomfort and inconvenience of bowel preparation may affect the acceptability and uptake of colonoscopy in screening programs.

The present study illustrated that there is a statistically significant difference between four groups of patients undergoing colonoscopy related to difficult visualization of the colon, canceled and repeated colonoscopy. (Johnson et al., 2014); was in the same line with the present study which revealed that; a patient education program administered by health care professionals increases patient compliance, improves quality, and decreases repeat examinations and costs. The use of both verbal and written instructions, compared with written instructions only, is an independent predictor of adequate bowel preparation quality. Educational tools such as booklets, information leaflets, animations, and visual aids should be standardized and validated, and should be effective across a range of health literacy and education levels. The use of a novel patient educational booklet on pre - colonoscopy preparation resulted in better bowel preparation quality scores than those achieved using conventional instructions.

The majority of the patients in all both two groups of the study were complained of abdominal pain and discomfort. (Weilan, et al., 2015); mentioned that; Abdominal pain or distension developed after colonoscopy has been a common phenomenon in clinical practice. Progression has been made by replacing the insufflated air for good visualization of the colon, Also, (American Association of Gastrointestinal Endoscopy, 2011); mentioned that; the most commonly reported minor complications of colonoscopy are abdominal distension (bloating) and abdominal pain and/or discomfort. Appropriate techniques, such as avoiding and reducing endoscope looping and minimizing air insufflation should help reduce these symptoms.

Finally, it can be concluded that educating colonoscopy patient using different nursing educational methods as audiovisual aids are considered a cornerstone in achieving accepted level of bowel cleanliness; decrease cost and early detect any abnormalities in the colon.

\section{Conclusions}

Based on the results of the present study, it can be concluded that

- The mean score level of BBPS in the study group $(6.7 \pm 1.2)$ was higher than that score in the control group (2.7 \pm 2.4$)$. Also, more than half of patients at study group $(56.7 \%)$ have an excellent level of bowel cleanliness while more than half of patients in control group (53.3\%) have a bad level of bowel cleanliness.

- The incidence of colonoscopy problems and complications in patients at study group was less than that of patients at control group except abdominal pain or discomfort and abdominal bloating.

\section{Recommendations}

- Relevant written and visual information to facilitate educating patients about proper preparation of the bowel for colonoscopy.

- Sufficient information about signs and symptoms of the potential complications and the importance seeking rapid medical advice.

- Gastro Endoscopy unit should specify the procedure time, at least, three days after receiving colonoscopy request from medical or surgical units so as to give a chance for good preparation of colon.

\section{References}

1. Allen J., (2010): Quality Colonoscopy, an Issue of Gastrointestinal Endoscopy Clinics, vol. 20, No. 4, p. 79. 
2. American Association of Gastrointestinal Endoscopy (2011): Gastrointestinal Endoscopy journal, Volume 74, No. 4: 745 - 752.

3. American Association of Gastrointestinal Endoscopy (2011): Gastrointestinal Endoscopy journal, Volume 74, No. 4: 745 - 752. Available at:www.giejournal.org.Accessed at:3/12/2011.

4. American Cancer Society, (2015): Colorectal cancer prevention and early detection. Availableat:http://www.cancer.org/cancer/colona ndrectumcancer/moreinformation/colonandrectu mcancerearlydetection/colorectal-cancer-earlydetection-symptoms-of-crc.Accessed at: 19/4/2015.

5. Assiut University Hospital Statistical Records (2014): Internal medicine and Gastroendescopy center records, No 4, pp. 335- 498.

6. Bastable S., Gramet P., Jacobs D., \& Sopczyk D., (2011): Health Professional as Educator: Principles of Teaching and Learning, 5th ed., Jones and Bastable publisher Company, Chapter 12, P. 463.

7. Chan W., Saravanan A., \& Manikam J., (2011): Appointment waiting for times and education level influence the quality of bowel preparation in adult patients undergoing colonoscopy, BMC Gastroenterology journal, 11:86.

8. Floch M., Floch N., Pitchumoni C., Rosenthal R., \& Scolapio J., (2010): Netter's Gastroenterology, $9^{\text {th }}$ ed., Elsevier Company, Chapter 29, P. 341.

9. Green D., (2015): Colonoscopy, Proctology Specialists. Available at: Proctologyspecialists.com/procedures/colonosco py. Accessed:5/3/2015.

10. Habr-Gama A., Arruda Alves P., \& Rex D., (2015): Indications and contraindications for colonoscopy. Available at: http://www.gastrohep.com/ebooks/ebook.asp?bo $\mathrm{ok}=1405120800 \& \mathrm{id}=2$. Accessed at 17/8/2015.

11. Hassan C., Bretthauer M., Kaminski M. , Polkowski M., Rembacjen B., Saunders B., Benamuzig R., Holme O., Green S., Kuiper T., Marmo R., Omar M., petruziello L., Spada C., Zullo A., \& Dumonceau J., (2013): Bowel preparation for colonoscopy: European Society of Gastrointestinal Endoscopy (ESGE) Guidelines, Endoscopy journal; 45: 142-150.

12. Henry, K., (2015): Rural vs. urban residence affects risk-appropriate colorectal cancer screening.Availableat:http://www.researchgate.n et/publication/233878296_Rural_vs_Urban_Resi dence_Affects_RiskAppropriate_Colorectal_Can cer_Screening.Accessed at 25/7/2015.
13. Johnson D., Barkun A., Cohen L., Dominitz J., Kaltenbach T., Martel M., Douglas J., Robertson D., Boland C., Giardello F., Lieberman D., Levin T., \& Rex D., (2014): Optimizing Adequacy of Bowel Cleansing for Colonoscopy: Recommendations From the US Multi-Society Task Force on Colorectal Cancer, American journal of Gastroenterology, doi:10.1038/ajg.272 .

14. Mattar M., Lough D., Pishvaian M. \& Charabaty A., (2011): Current Management of Inflammatory Bowel Disease and Colorectal Cancer, Gastrointestinal cancer research, vol. 4(2): 53-61.

15. Muma R., \& Lyons B., (2012): Patient Education: A Practical Approach, 2nd ed., Jones and Bartlett Company, Chapter 2, P. 12.

16. Nolan D., (2011): Anemia. Available at: http://www.colonoscopy.com/conditions/anemia. Accessed at 12/8/2011.

17. Nordqvist C. (2013): what is ulcerative colitis? .Available at: http://www.medicalnewstoday.com/articles/1637 72.php.Accessed at 29/8/2013.

18. Peery A., Dellon E., \& Lund J., (2012): Burden of gastrointestinal disease in the United States, Gastroenterology journal; 143:1179-87.

19. Rosenfeld G., Krygier D., \& Enns R., (2010): The impact of patient education on the quality of inpatient bowel preparation for colonoscopy. Canadian Journal of Gastroenterology, vol. (24) pp.543-6.

20. Sherid M., Samo S., \& Sulaiman S., (2013): Complications of Colonoscopy, Colonoscopy and Colorectal Cancer Screening - Future Directions, Dr. Marco Bustamante (Ed.), ISBN: 978-953-51-0949-5, InTech, DOI: 10.5772/53202. Available at: http://www.intechopen.com/books/colonoscopyand-colorectal-cancer-screening-futuredirections/complications-ofcolonoscopy.Accessed at 13/2/2013.

21. Shieh T., Chen M., Chang C., Hung C., Chun Hu K., Che Kuo Y. , Chuan Shih S., \& Wang W., (2013): Effect of Physician-Delivered Patient Education on the Quality of Bowel Preparation for Screening Colonoscopy, Gastroenterology Research and Practice, ArticleID 570180.Availableat:http://dx.doi.org/1 0.1155/2013/570180.Accessedat:10/11/2013.

22. Smeltzer S., Bare B., Hinkle J., \& Cheever K., (2008): Brunner \& Suddarth's textbook of medical- surgical nursing, Anatomy of the digestive system, 11th ed., Lippincott Williams and Wilkins Company, Chapter 34, P. 11361137. 
23. Talley N., \& Kane S., (2010): Practical Gastroenterology and Hepatology: Small and Large Intestine and pancreas, $3^{\text {rd }}$ ed., WileyBlackwell Company, Chapter 7, P. 413.

24. Urden L., Stacy K., \& Lough M., (2014): Critical Care Nursing, Diagnosis, and Management, 7th ed., Elsevier Company, Chapter 1, P. 80.

25. Van Jaarsveld C., Miles A., Edwards R., \& Wardle J., (2006): Marriage and cancer prevention: does marital status and inviting both spouses together influence colorectal cancer screening participation?, Journal of Med Screen. 13(4):172-6

26. Voiosu T., Ratiu I., Voiosu A., Iodache T., Schipor A., Cristian B., Sporea I., \& Voiosu R., (2013): Time for individualized colonoscopy bowel- preparation regimens. A randomized controlled trial comparing sodium pico sulfate and magnesium citrate versus 4- liters split dose polyethylene glycol, a journal of gastrointestinal liver disease, vol. 22 No. 2, pp. 129 - 134.

27. Warner J., (2014): Ulcerative Colitis: The Importance of Screening for Colorectal Cancer. Available at:http://www.everydayhealth.com/hs/ulcerativecolitis-treatment-management/colorectal-cancerscreening/.Accessed at: 24/7/ 2014.

28. Weilan W., Chen Y., Yao Y., Yang Y., Zhao Q., \& Qiu L., (2015): Transcutaneous electric acupoint stimulation at Jiaji points reduce abdominal pain after colonoscopy: a randomized controlled trial, International journal of clinical experience, Vol. 8(4):5972-5977.

29. Wikipedia, the free encyclopedia (2015): colonoscopy. Available at: https://en.wikipedia.org/wiki/Colonoscopy.Acces sed at 13/3/2015

30. Williams B., \& Paul P., (2009): Brunner \& Suddarth's Canadian textbook of medicalsurgical nursing, Assessment of digestive and gastrointestinal function, 2nd ed., Lippincott Williams and Wilkins company, Chapter 34, P. $1051-1053$.

31. Zauber A., Winawer S., \& O'Brien M., (2012): Colonoscopic Polypectomy and longterm prevention of colorectal-cancer deaths, New England Journal of Medicine, vol. 20(6), 366:687-696.

32. Zuccala B., (2015): Improving the quality of bowel preparation for colonoscopies. Available at:

http://www.endonurse.com/articles/2015/07/impr oving-the-quality-of-bowel-preps-for-

colonosc.aspx.Accessed at 3/5/2015.
33. Zúñiga V., Moreno-de-Vega V., \& Boix J., (2012): Preparation for colonoscopy: types of scales and cleaning products, Revista Espanola de Enfermedades Digestivas Journal (Madrid), Vol. 104. N. 8, pp. 426-431. 